\title{
ALGUNS CONHECIMENTOS SÔBRE NUTRIÇÃO LIGADOS À GESTAÇÃO E AO PUERPÉRIO
}

WITT, A. - Alguns conhecimentos sôbre nutrição ligados à gestação e ao puerpério. Rev. Saúde públ., S. Paulo, 5:97-102, 1971.

REsUMo - Apresentação dos resultados relativos aos conhecimentos de nutrição, ligados à gestação e ao puerpério, obtidos através de uma investigação social. Foi verificado que a maioria das entrevistadas acredita que a gestante deve comer o que tem vontade, a fim de que o bebê não seja prejudicado; também há necessidade de dieta pós-parto com a duração de 40 a 60 dias, de acôrdo com o parecer de mais de $\mathbf{5 0 \%}$ das interrogadas. Os alimentos citados com mais frequêencia como sendo de consumo contra indicado, após o parto, foram a carne de porco e o pescado. O leite, a cerveja malzbier e a canjica foram os alimentos apontados, com mais frequência, como sendo de uso conveniente para a puérpera ter bastante leite.

UnItermos - Hábitos alimentares *; Gestação *; Puerpério *.

\section{INTRODUCAO}

A situação alimentar da humanidade é das mais sérias, estimando-se que pelo menos, dois-têrços da população da América Latina é atingida pela subnutrição. 0 problema da alimentação apresenta inúmeras facetas, tanto técnicas, políticas, econômicas, quanto sociais; entre estas podem ser lembradas as barreiras educacionais, as tradições, os costumes, os tabus, as superstiçōes, os preconceitos, as religiōes. Isto indica que o consumo de alimentos liga-se não apenas à existência quantitativa dos mesmos e à possibilidade de sua aquisição em têrmos monetários; sua menor ou maior utilização está condicionada a padrões culturais específicos da população; os conhecimentos sôbre nutrição e hábitos alimentares, de que são portadores os indivíduos, determinam em grande e larga escala o que é consumido, podendo ser parcialmente responsabilizados pelo aparecimento ou agravamento de problemas. Desde logo se evidencia a importância do fator conhecimento da população, que é considerado mesmo, um dos determinantes do comportamento humano.

Seria de interêsse lembrar que é raro as pessoas serem ignorantes no sentido de desconhecerem, totalmente, o que lhes é apresentado. Geralmente os indivíduos têm um conhecimento que pode, ou não,

Recebido para publicação em 15-3-1971.

(1) Da Disciplina Fundamentos Socials e Culturais da Saúde Pública do Departamento de Prática de Saúde Pública da Faculdade de Saúde Pública da USP. Av. Dr. Arnaldo, 715 Săo Paulo, SP, Brasil. 
WITT, A. - Alguns conhecimentos sôbre nutrição ligados à gestação e ao puerpério. Rev. Saúde puibl., S. Paulo, 5:97-102, 1971.

estar de acôrdo com o que é apregoado por outro grupo ou pessoa. Isto se reveste de grande importância, quando êsse conhecimento difere do científico, tido como certo, apresentado pelas autoridades educacionais formais, como as que se dedicam à nutrição. Não é difícil ocorrer a rejeição do conhecimento transmitido, quando não forem obedecidos os princípios sociais recomendados na implantação de mudanças. No caso da nutrição, freqüentemente se procura uma mudança de comportamento no sentido de os indivíduos consumirem corretamente os alimentos. Como exemplo, podem ser citadas as instituições de saúde que contam com serviços de higiene maternoinfantil, onde são dadas orientações ou recomendaçōes às clientes, acêrca do uso de alimentos durante a gestação e o puerpério.

E possível que noções de educação alimentar estejam sendo dadas em cursos especializados de nutrição, em serviços pré-nupciais ou pré-natais e outros, acreditando-se que haverá uma aceitação do que é transmitido, ou melhor, de que haverá uma conduta correspondente favorável, porque se está dando um conhecimento para quem não o possui. Mas pode ocorrer que o grupo ouvinte já tenha um conhecimento sôbre o assunto, igual ou diferente daquêle apresentado. Se fôr igual ao que lhe é transmitido, surge o desperdício de tempo, pessoal e material das instituições; se o conhecimento dos alunos fôr diferente, as novas informações poderão encontrar dificuldades em serem aceitas, especialmente se estiverem presentes fatôres de ordem emocional ou sobrenatural, que são de muita importância no consumo de alimentos.

Os padrões de comportamento alimentar variam bastante: alguns são largamente difundidos e outros restritos a grupos definidos ou épocas específicas. Assim, o consumo de carne de cão é considerado impróprio por muita gente; é crença bastante difundida entre nós a existência de alimentos "frios" ou "quen- tes", interferindo esta qualificação no consumo. Entre as proibições transitórias, impostas a grupos, citaremos alguns exemplos ligados à gestação e ao puerpério. Em um estudo realizado entre gestantes da Louisiania foi verificado que elas não comiam vegetais, porque a côr verde dos mesmos afetaria, posteriormente, o leite materno ${ }^{1}$; outras observações indicam que gestantes não comem frutas de árvores que têm espinhos, porque acreditam que êstes machucarão a criança; também não é consumido o peixe, em certas regiões, durante a gestação, ou após o parto, para que seja evitada a morte da criança ${ }^{2}$.

Foram obtidos, em pesquisa por nós realizada, alguns dados referentes ao conhecimento existente sôbre os estados fisiológicos especiais da gestação e puerpério.

Estes resultados, além de fornecerem traços culturais de uma dada população, mostram que além das variáveis quantitativas e qualitativas, normalmente observadas nos programas de educação alimentar destinada a gestantes, as características sócio-culturais também merecem atenção.

\section{P ROCEDIMENTOS}

Para que se obtenha eficiência nos trabalhos relativos à educação alimentar, além da consideração do método educativo a ser utilizado, é necessária a definição clara e precisa do problema estudado.

Esta prática permite a identificação do que precisa ser mudado pelo processo educativo. Quando se pretende modificar uma situação existente, através da educação, é importante observar os aspectos sócio-culturais da população, dentre os quais se destacam os seus conhecimentos e hábitos alimentares. E através da análise do que existe que se verifica o que precisa ser modificado. 
WITT, A. - Alguns conhecimentos sôbre nutrição ligados à gestacão e ao puerpérlo. Rev. Saúde pribl., S. Paulo, 5:97-102, 1971.

A pesquisa por nós efetuada, tinha por objetivo a verificação dos habitos alimentares e conhecimentos sôbre nutrição dos alunos matriculados nos Centros de Aprendizado Doméstico, do Serviço Social da Indústria (SESI), tendo em vista o fornecimento de subsídios para a elaboração dos respectivos currículos. Os resultados desta investigação poderiam também servir para a avaliação dos cursos no que se refere a sua eficiência em termos de mudança dos conhecimentos e dos hábitos alimentares dos alunos.

No presente trabalho, são apresentados apenas os resultados referentes aos conhecimentos sôbre nutrição ligados à gestação e ao puerpério.

$\mathrm{Na}$ investigação foram abordados os seguintes tópicos: dados sócio-econômicos, hábitos alimentares, conhecimentos sôbre nutrição, disponibilidade de alimentos e material eletro-doméstico.

Foi verificado que na literatura existente sôbre o assunto, os alimentos encontram-se classificados de diferentes formas de acôrdo com o interêsse especial do pesquisador, uma vez que as proteínas diferem dos hidratos de carbono $\mathrm{e}$ das gorduras, em vários pontos. Consideraremos suficiente e apropriado para nossa investigação o agrupamento dos alimentos nas categorias: plásticos, energéticos e protetores. Lembramos que alimentos plásticos são os que fornecem materiais anabólicos e de manutenção, como por exemplo as proteínas. Alimentos energéticos são os que satisfazem a necessidade de proporcionar energia ao organismo, como protetores, também conhecidos por reguladores, regulam o metabolismo corporal, pertencendo a tal categoria predominantemente os minerais $\mathrm{e}$ as vitaminas.

No processo de coleta de dados foi usado como instrumento, o formulário, considerado o mais indicado, devido especialmente à heterogeneidade do universo pesquisado. Tendo em vista a precisão dos resultados, foi feito um pré-teste e as entrevistadoras responsáveis pela coleta de dados foram treinadas teórica e pràticamente. A coleta realizou-se entre os dias 4 e 17 de fevereiro de 1968.

0 universo era constituído por alunas matriculadas pela primeira vez nos Cursos de Aprendizado Doméstico. Para o presente estudo, foram selecionados os Centros de Aprendizado Doméstico, números 13,20 e 29, localizados respectivamente no Cambucí, Guarulhos e Rudge Ramos (S.P.). Nestas instituições eram ministrados 4 cursos, um inespecífico e 3 destinados a categorias sociais distintas, conhecidos pelas seguintes denominações:

1. Curso Básico, que inclui jovens indiscriminadamente, sendo êste o curso que apresenta o maior número de alunas.

2. Agrupamento (Donas de Casa) : destina-se a jovens casadas.

3. Agrupamento (Bandeirante de Saúde).

4. Agrupamento (Adolescentes) : abrange jovens de 12 a 15 anos.

Para a seleção da amostra, probabilística simples, foram entregues a tôdas alunas senhas numeradas. Como o maior número de alunas pertence ao Curso Básico, optou-se pela escolha de $25 \%$ destas e $50 \%$ das integrantes dos demais cursos.

Foram escolhidas por sorteio as primeiras pessoas entrevistadas; as demais foram interrogadas segundo o seguinte procedimento: cada 4 alunas dos Cursos Básicos e cada segunda dos outros cursos. Foram entrevistadas 184 alunas.

\section{RESULTADOS OBTIDOS REFERENTES A CONHECIMENTOS SOBRE NUTRIÇA LIGADOS A GESTAÇAO}

Os conhecimentos ligados à gestação' foram obtidos através de questões que versavam: 1 . sôbre a necessidade da mãe "comer por 2 pessoas", para que o bebê nascesse forte; 2 . sôbre o fato de o feto ser prejudicado, caso a gestante não comesse o que desejasse; 3 . sô- 
WITT, A. - Alguns conhecimentos sôbre nutrição ligađos à gestação e ao puerpério. Rev. Saúde puibl., S. Paulo, 5:97-102, 1971.

bre nascimento de gêmeos, devido ao consumo de "bananas gêmeas", pela mulher grávida.

Pela Tabela verifica-se que as respostas afirmativas às questões podem evidenciar a existência de um tabú.

Verifica-se que entre os conhecimentos pesquisados ligados à gestação, o citado com maior freqüência refere-se à necessidade da futura mãe comer o que tem vontade, a fim de que o bebê não seja prejudicado.

Como conseqüências do fato da mulher grávida não comer o que tem vontade foram apontadas as seguintes: a criança nasce com mancha, a criança nasce fraca, a criança nasce doente, a criança nasce defeituosa, a criança nasce prematura e a criança nasce com a "bôca aberta" (fenda palatina, lábio leporino). ter bastante leite e a necessidade de dieta pós-parto.

A questão: "Para a mãe ter bastante leite, o que deve comer e beber depois do bebê nascer" analisada de acôrdo com os extratos de alimentos utilizados na presente investigação, apresenta os seguintes resultados:

- alimentos plásticos ........ 43\%

- alimentos energéticos ...... 9\%

- alimentos protetores ...... 29\%

- outros ................ 19\%

(Fonte: quadro n. ${ }^{\circ} 11-$ WITT $^{2}$ )

Observa-se que são citados com maior freqüência os alimentos plásticos e dentre êstes, o leite aparece em primeiro lugar. As frutas se sobressaem entre os alimen-

T A B E L A

Conhecimento de alunas de 3 Centros de Aprendizado Doméstico de São Paulo, ligado à gestação.

\begin{tabular}{|c|c|c|c|c|c|c|c|}
\hline \multirow[b]{2}{*}{ Tipo de resposta } & \multicolumn{2}{|c|}{$\begin{array}{l}\text { Para o bebe nas- } \\
\text { cer forte a mâe } \\
\text { deve "comer } \\
\text { por 2" }\end{array}$} & \multicolumn{2}{|c|}{$\begin{array}{l}\text { A mulher grávida } \\
\text { deve comer o que } \\
\text { tem vontade p/ } \\
\text { não prejudicar o } \\
\text { bebe }\end{array}$} & \multicolumn{2}{|c|}{$\begin{array}{l}\text { Se a gestante co- } \\
\text { mer "banana } \\
\text { gêmeas" terá } \\
\text { gêmeos }\end{array}$} & \multirow[t]{2}{*}{ Total } \\
\hline & N.o & $\%$ & N.・ & $\%$ & N.• & $\%$ & \\
\hline Sim & 34 & 18 & 97 & 53 & 22 & 12 & 153 \\
\hline Não & 132 & 72 & 65 & 35 & 123 & 67 & 320 \\
\hline Não Sel & 17 & 9 & 22 & 12 & 39 & 21 & 78 \\
\hline Inuttlizada & 1 & 1 & - & - & 一 & 二 & 1 \\
\hline Total & 184 & 100 & 184 & 100 & 184 & 100 & 552 \\
\hline
\end{tabular}

\section{RESULTADOS OBTIDOS REFERENTES A CONHECIMENTOS SOBRE NUTRICAOO LIGADOS AO PüERPERIO}

Os conhecimentos ligados ao puerpério tiveram por base, perguntas referentes ao consumo de alimentos para a puérpera tos protetores e na categoria de outros, destaca-se a cerveja Malzbier e a canjica, com as respectivas porcentagens: $35 \%$ e $23 \%$. Se considerarmos o total de entrevistas (184) verificaremos que $24 \%$ delas apontaram o leite e $17 \%$ a cerveja. Pouco mais de $47 \%$ das en- 
WĩTT, A. - Alguñs conhecimèntos sôbre nutricăa ligađos à gestação e ao puerpério. Rev. Saúde puibl., S. Paulo, 5:97-102, 1971.

trevistadas alegaram não saber o que a puérpera deve comer ou beber para ter leite em abundância.

A maioria das entrevistadas acredita ser necessário, para a mulher que teve um filho, seguir uma dieta alimentar. Apenas $9 \%$ delas acha que tal prática é desnecessária, enquanto que $15 \%$ não sabe se é, ou não, necessária tal dieta.

Quanto à duração da mesma, a maioria julga ser necessária a observação de dieta alimentar por 40 a 60 dias.

Duração da dieta: $\quad \%$

menos de 30 dias $\ldots \ldots \ldots \ldots \ldots . . .15$

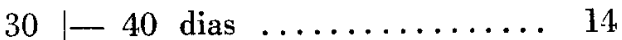

$40-60 \operatorname{dias} \ldots \ldots \ldots \ldots \ldots \ldots .65$

$60-90$ dias $\ldots \ldots \ldots \ldots \ldots \ldots . .9$

+ de 90 dias $\ldots \ldots \ldots \ldots \ldots . .69$

Total ...................... 100

As 102 entrevistadas que afirmam não poder a puérpera comer de tudo, apontaram 137 alimentos impróprios. Agrupando-os de acôrdo com os extratos alimentares estabelecidos, foi verificado que os alimentos componentes do grupo dos plásticos, são os mais citados e dentre êsses, destaca-se a proibição do uso de carne de porco e de pescado.

A distribuição geral dos alimentos, que não podem ser consumidos pela mulher após o parto, é a seguinte:

— alimentos plásticos ......... 41

- alimentos energéticos ........ 9

— alimentos protetores ........ 11

- outros alimentos .......... 39

Total ............... 100

Proibição de consumo de carne de porco e pescado pela puérpera

\section{Alimento}

Carne de porco ............. 39

Pescado .................. 34

Outros $\ldots \ldots \ldots \ldots \ldots \ldots \ldots .27$

Total ............... 100

\section{COMENTARIOS}

Os resultados apresentados nos dão uma idéia geral dos conhecimentos sôbre nutrição ligados à gestação e ao puerpério, de que são portadoras as alunas matriculadas nos cursos de Aprendizado Doméstico de Cambuci, Guarulhos, Rudge Ramos e redondezas.

Foi verificado que é bastante difundida a crença de que a gestante deve comer o que tem vontade, para que seu filho não seja prejudicado. Aparentemente, portanto, maior atenção deveria ser dedicada a êste conhecimento, por ser êle o mais comum entre os estudados.

De grande utilidade seria a realização de investigação mais profunda, a fim de se verificar melhor, quais são os alimentos que compõem o cardápio das que acreditam que a gestante precisa comer por 2 , para o bebê nascer forte. Isto porque, é recomendável o uso de alimentos que não provoquem o aumento de pêso, tendo-se em vista evitar dificuldades que podem surgir por ocasião do parto, decorrentes de uma superalimentação ou de uma alimentação imprópria. Seria interessante tentar uma redução do consumo de alimentos que ocasionam aumento de pêso, substituindo-os por outros de comprovada importância na gestação, como por exemplo, o uso de alimentos que proporcionem maior fonte de ferro, especialmente a partir do quinto mês, quando há uma baixa na taxa de hemoglobina da gestante, decorrente da expoliação de ferro pelo feto.

Este fato, alimentação inadequada, pode exigir uma mudança social, que seria concretizada no consumo correto de alimentos, durante a gestação.

Lembramos ainda, que $9 \%$ das entrevistadas responderam que não sabem se a gestante deve comer por dois para que o filho nasça forte; $12 \%$ deram tal resposta quanto à necessidade da gestante comer o que tem vontade, a fim de que o bebê não seja prejudicado. Estas respostas podem indicar a ausência de co- 
WITT, A. - Alguns conhecimentos sốbre nutrição ligados à gestaçâo e ao puerpério. Rev. Satide pribl., S. Paulo, 6:97-102, 1971.

nhecimento sôbre as questões, sendo possível a aquisição de um conhecimento certo ou errado. Estas pessoas constituem um grupo que, teòricamente, vai oferecer menores resistências para aceitar um conhecimento correto que lhe fôr transmitido em programas de educação alimentar. Neste caso, não há necessidade de ser substituído um conhecimento por outro, o que implicaria em duas operaçōes: retirada de um e subseqüente substituição por outro. A mudança, aqui necessária, diz respeito ao corpo total de conhecimentos do indivíduo que seria acrescido de mais um conhecimento, sem retirada de outro. Yortanto, constitui um grupo de trabalho mais fácil, com menores probabilidades de encontro de resistências. Quanto ao puerpério verifica-se, também, que nem todas as entrevistadas tem um conhecimento coincidente com o científico. A cerveja Malzbier é considerada como sendo de uso conveniente, para que a mãe tenha bastante leite, por $24 \%$ das entrevistadas, enquanto $1 \% \%$ afirmam que o consumo de canjica dá resultado idêntico, o que não corresponde à opinião médica.

Mais de 55\% das interrogadas acreditam ser preciso a observação de uma dieta alimentar pela mãe, após o nascimento do bebê, o que na verdade não é obrigatório em situação pós-parto normal. Por exemplo, não há contra indicação médica do consumo de peixe, um dos alimentos apontados como impróprios, na presente investigação, por 20 pessoas; pelo contrário, - uso dêste alimento pode ser recomendável, constituindo uma rica fonte de fósforo.

Pelo exposto, foi verificado que os conhecimentos ligados ao puerpério e gestação, do corpo discente dos Centros de Aprendizado Domésticos pesquisados, são inadequados, sendo aconselhável programações específicas baseadas nos conhecimentos das alunas, aqui salientados.

Tomando por base as maiores freqüências encontradas, ligadas às questōes co- locadas, poder-se-ia apontar como prioritária a transmissão de noçōes acêrca da alimentação da gestante, condicionada ao que ela tem vontade de comer, e seguimento de dieta alimentar pós-parto. Estas programações poderiam contribuir para a melhoria dos padrões alimentares das alunas quando elas se encontrarem na situação de gestantes ou puérperas, podendo também serem atingidas, através delas outras pessoas que fazem parte dos seus grupos sociais.

Acreditamos que estas crenças são igualmente bastante difundidas em outros meios, cuja população apresenta características sociais semelhantes às pessoas por nós entrevistadas. Talvez, poder-se-ia mesmo sugerir a inclusão de tópicos referentes ao consumo pela gestante do que tem vontade, e a dieta pós-parto, nos programas de educação alimentar, por ventura realizados.

WITT, A. - [Food habits related to pregnancy and post-delivery periods]. Rev. Sanide puibl., S. Paulo, 5:97-102, 1971.

Summary - The results relative to the food habits connected to pregnancy and post-delivery - obtained through a social research - are presented. Interviewed women believe they should eat at will for the baby's sake; the necessity of a postdelivery (40 to 60 days) was also stressed by more than $50 \%$ of the interviewed. Pork and fish were considered harmfull for the post-delivery diet; milk, black beer and a typical soup made with white maize were considered as the appropriate food for a bigger lactation.

UNITERMS - Food habits *; Pregnancy *; Post-delivery *.

\section{REFERENCIAS BIBLIOGRAFICAS}

1. RODINSON, M. - Gôsto não se discute. A saúde do mundo, abr. 1969. p. 24-26.

2. WITT, A. - Hábitos alimentares e conhecimentos sôbre nutrisáo de alunos dos Cursos de Aprendizado Doméstico do Servico Social da Indústria. Săo Paulo, Faculdade de Saúde Pública, 1970. [mimeografado]. 